\title{
Evidenciação voluntária das práticas ambientais: um estudo nas grandes empresas brasileiras de papel e celulose
}

\author{
Ana Paula Borges ${ }^{\mathrm{a}, *}$, Fabrícia Silva da Rosa ${ }^{\mathrm{b}}$, Sandra Rolim Ensslin ${ }^{\mathrm{c}}$ \\ a,*anaborges00@hotmail.com, UFSC, Brasil \\ bfabriciasrosa@hotmail.com, UFSC, Brasil \\ 'sensslin@gmail.com, UFSC, Brasil
}

\section{Resumo}

Esta pesquisa descritiva tem por objetivo investigar a evidenciação voluntária das vinte maiores empresas brasileiras de papel e celulose. Como resultado, constata-se que, na grande maioria das instituições analisadas, as políticas ambientais estão amplamente declaradas, porém aspectos financeiros e ambientais apresentam, em sua grande maioria, informações de caráter descritivo.

Palavras-chave

Evidenciação ambiental voluntária. Práticas ambientais. Papel. Celulose.

\section{Introdução}

0 período de mudanças na economia mundial vem sendo apontado por muitos estudiosos do assunto como o período de transição de uma Sociedade Industrial para uma Sociedade do Conhecimento, pois aos demais recursos existentes e até então valorizados e utilizados na produção terra, capital e trabalho -, se junta o conhecimento, alterando, principalmente, a estrutura econômica das nações e, sobretudo, a forma de valorizar o ser humano (MARTINS, 2000, p. 1).

Essa transição para a era do conhecimento trouxe, portanto, novas preocupações e novos objetivos dentro das organizações; dentre essas preocupações, pode-se destacar a gestão ambiental.

Nas empresas, observa-se que apenas a visão do lucro é insuficiente para alcançar os objetivos da entidade. A longo prazo, para a empresa possuir continuidade, ela deve atender às necessidades de todos os agentes envolvidos: clientes, governos, comunidade, funcionários e acionistas. Dentre essas necessidades, destaca-se o bem-estar dos próprios funcionários e da sociedade, com ênfase no aspecto ambiental (ALBERTON; CARVALHO; CRISPIM, 2004).
Tal cenário representa também certo estado de conscientização do consumidor, na medida em que os fatores preço e qualidade não são os únicos a serem considerados quando da aquisição de um produto ou da obtenção de um serviço. Dessa forma, esse fato também interessa aos investidores, pois quanto maior a quantidade de clientes e melhor a imagem da organização na sociedade, entre outros fatores, mais vantagens terão os investidores ao aplicar seu capital nessas empresas. Visando à captação de clientes e de investidores, o diferencial de possuir gestão ambiental pode gerar valor agregado para as organizações, havendo, portanto, a necessidade de divulgar suas práticas ambientais para as diferentes partes interessadas.

Segundo Paiva (2009), o caráter global de grande parte das empresas sugere que estas devam deixar transparecer um grau de preocupação e de amadurecimento elevado, demonstrando a existência de uma consciência ambiental desenvolvida. Assim, quando a empresa passa a valorizar sua relação com o meio ambiente e a tomar medidas preventivas, sua imagem perante a opinião pública tende a apresentar conotação diferenciada. 
Há uma grande movimentação social e científica com o intuito de promover a avaliação das informações ambientais evidenciadas; tal avaliação é também denominada evidenciação ambiental (environmental disclosure). Segundo Cormier et al. (2004), a evidenciação ambiental é definida como informação comunicada às partes interessadas por meio dos relatórios anuais e ambientais para que as organizações obtenham legitimidade.

A evidenciação das práticas sociais e ambientais responsáveis pode agregar valor às organizações, pois, além de promover a transparência das informações a todos os seus stakeholders, a atividade de evidenciação encontra-se em conformidade com as leis. Porém, a evidenciação ambiental ainda não é uma realidade igual para todas as organizações, dificultando a evidenciação padronizada entre empresas, bem como a avaliação dessas informações tanto pela própria empresa como para os stakeholders.

Diante dessa situação, tem-se esta questão como problema: "Quais são as práticas ambientalmente responsáveis das empresas de papel e celulose e de que forma estas práticas são divulgadas ao público com o qual tais empresas se relacionam?"

Com o intuito de responder à pergunta da pesquisa, o presente trabalho objetiva investigar a evidenciação voluntária das práticas ambientais nas vinte maiores empresas brasileiras de papel e celulose, conforme critérios de seleção definidos no item 3.2 - População e amostra - desta pesquisa.

\section{Plataforma teórica}

Esta seção apresenta a fundamentação teórica que informa o desenvolvimento deste artigo e está subdividida em dois itens: (i) Contabilidade e meio ambiente e (ii) Evidenciação ambiental.

\subsection{Contabilidade e meio ambiente}

Durante muito tempo, a ampla maioria dos ambientalistas foi contra o crescimento econômico, pois se considerava que o desenvolvimento das organizações estava diretamente ligado à degradação do meio ambiente. Porém, a partir dos anos 70 do século $X X$, iniciou-se um período de transição de pouco mais de uma década, em que a opinião desses especialistas apresentou uma mudança. Os ambientalistas, então, começaram a defender o desenvolvimento econômico, pensando em um modo sustentável para o meio ambiente.

Percebe-se que, com o desenvolvimento sustentável, as corporações tornaram-se responsáveis por um grande número de interesses. Os principais interessados são os acionistas dessas corporações, que necessitam de informações sobre a situação dos ativos e sobre os resultados da empresa. Além disso, os acionistas querem estar protegidos contra obrigações de ordem ambiental.

A constatação de que a capacidade assimilativa dos ecossistemas e de que a capacidade de regeneração dos recursos naturais ocorriam a taxas incompatíveis com o acelerado desgaste imposto à natureza inspirou o surgimento de um novo conceito, também conhecido como desenvolvimento sustentável. Este coloca o setor produtivo em foco como ator essencial para seu alcance e impõe aos formuladores de políticas públicas a tarefa de adotar medidas que induzam o setor produtivo a estabelecer metas que estejam inseridas neste novo conceito de desenvolvimento. Dentro desse novo conceito, busca-se o incremento e/ou a manutenção da produtividade, acompanhada de indicadores de justiça social e de qualidade do processo produtivo, do produto e das condições ambientais (BARATA, 1995).

Para Barbieri (2007), a solução dos problemas ambientais - ou sua minimização - exige uma nova atitude dos empresários e administradores, que devem passar a considerar o meio ambiente em suas decisões e adotar concepções administrativas e tecnológicas que contribuam para ampliar a capacidade de suporte do planeta.

Expandindo-se o horizonte além do interesse dos acionistas, observa-se um grande número de interessados nas possíveis obrigações ambientais da empresa: consumidores, competidores, vizinhos, investidores, empregados, instituições financeiras, público em geral, governo, grupos de formadores de opinião, mídia, comunidade científica e fornecedores. Esse público apresenta diferentes graus de interesse nas informações ambientais relativas às atividades empresariais. São os chamados $q$. Credores, por exemplo, têm interesse na informação ambiental a fim de calcular o risco de crédito. Investidores necessitam de informações sobre gastos e desempenho ambiental para tomar decisões de investimentos. Os empregados desejam condições adequadas de trabalho. 0 público em geral está cada vez mais está interessado em identificar como a companhia afeta o crescimento econômico do País. Frente a essas informações, a gestão ambiental começa a ser encarada como assunto estratégico dentro das organizações, o que tem se tornado um fator importante de competitividade.

Nesse contexto, inicia-se uma nova trajetória: as empresas começam a pensar na proteção ambiental para auxiliar - e não impedir - o crescimento, fazendo 
com que sejam competitivas no mercado. Dessa forma, admite-se a ideia de uma nova organização da economia a fim de torná-la ambientalmente sustentável. Uma forma de admitir esse novo panorama pode ser a inserção de novos métodos de gestão e gerenciamento (PFITSCHER, 2004).

A Contabilidade Ambiental, por sua vez, é de suma importância para que se possa analisar a valoração dos recursos naturais. Segundo Ferreira (2003, p. 59).

[...] 0 desenvolvimento da Contabilidade Ambiental é resultado da necessidade de oferecer informações adequadas às características de uma gestão ambiental.

Portanto, a Contabilidade focada no meio ambiente pode ser de grande utilidade no processo de comunicação entre entidades e sociedade no que se refere à defesa do meio ambiente: (i) fornecendo subsídio informacional para controlar impactos ambientais; (ii) fortalecendo a imagem de uma empresa socialmente responsável e fornecendo um conjunto de informações confiáveis para o público externo da sociedade sobre o meio ambiente. Diante da importância que tem o setor ambiental dentro das organizações, torna-se necessário evidenciar as práticas que são realizadas na busca do desenvolvimento sustentável.

A Contabilidade Ambiental é de suma importância para que se possa analisar a valoração dos recursos naturais. Para Braga (2007), essa valoração pode ser abordada sob três tipos de enfoque: (i) econômico: no aspecto microeconômico, informando efeitos pela procura dos seus produtos, do valor dos dividendos a serem pagos e custos ambientais; no aspecto macroeconômico, efeitos no cálculo do PIB e outros indicadores econômicos; socioempresarial apresenta à comunidade/sociedade o resultado das ações de preservação do meio ambiente; (ii) comportamental, que identifica o efeito produzido nos diversos usuários, sobre as políticas adotadas e informações contábeis fornecidas pelas empresas, em que respostas a tais perguntas serão fundamentais para a tomada de decisões; (iii) legal, que exerce um controle sobre o uso de recursos naturais.

Segundo Ferreira (2003, p. 59)

[...] 0 desenvolvimento da Contabilidade Ambiental é resultado da necessidade de oferecer informações adequadas às características de uma gestão ambiental.

Portanto, a Contabilidade, focada no meio ambiente, pode ser de grande utilidade no processo de comunicação entre entidades e sociedade no que se refere à defesa do meio ambiente: primeiro, identificando e fornecendo subsídio informacional para controlar impactos ambientais; segundo, fortalecendo a imagem de uma empresa socialmente responsável, fornecendo um conjunto de informações confiáveis para o público externo da sociedade sobre o meio ambiente.

Diante da importância que tem o setor ambiental dentro das organizações, torna-se necessário divulgar as práticas que são realizadas na busca do desenvolvimento sustentável. Existem diferentes maneiras de evidenciar os ativos das empresas, que podem ser indicados de forma numérica ou textual; note-se que ambas as formas contribuem para a divulgação das riquezas que as empresas possuem e são de suma importância para caracterizar as organizações.

\subsection{Evidenciação ambiental}

Segundo Kosztrzepa (2004), a evidenciação das informações ambientais das empresas pode ser feita de diversas formas, das quais, sem dúvida, irão beneficiar-se as empresas e os usuários das informações contábeis ao tomarem decisões mais confiáveis e seguras sobre as organizações.

Conforme Ferreira et al. (2009), para demonstrar seu compromisso com a sociedade e sua responsabilidade social, as empresas utilizam-se de diversos recursos, que vão desde campanhas de marketing até a divulgação de relatórios de ações sociais e ambientais.

0 termo evidenciação ambiental vem sendo utilizado no sentido de aperfeiçoar a comunicação da empresa. Assim, para Lins e Silva (2007), em Contabilidade, o termo disclosure é aplicado como sinônimo de evidenciação, abertura, evidenciação de informações quantitativas e qualitativas.

De acordo com Tinoco e Kraemer (2004), o objetivo da evidenciação é divulgar informações dos desempenhos econômico, financeiro, social e ambiental das entidades aos parceiros sociais, os stakeholders, considerando que os demonstrativos financeiros e outras formas de evidenciação não devem ser enganosos.

Salotti e Yamamoto (2005) apontam que uma das principais questões relativas à importância da evidenciação refere-se à percepção dos investidores em relação ao risco que a companhia oferece. Diversos estudos são realizados mostrando como o nível de evidenciação pode afetar a empresa e a grande maioria deles conclui que existe correlação entre o nível de evidenciação e a diminuição de custo de capital e risco.

Para esta pesquisa, há três níveis de evidenciação: (i) a completa, ou full disclosure, baseada na criação 
de uma cultura de mercado, isto é, na maximização da evidenciação de informações; (ii) a justa, que pressupõe o tratamento equitativo a todos os usuários, e (iii) a adequada, na qual se divulgam informações somente quando são relevantes para os usuários; esta pode ser feita de duas maneiras: obrigatória ou voluntária.

Assim, Nossa (2002) afirma que o disclosure ambiental pode ser feito de maneira obrigatória, quando exigido por leis e regulamentos, ou voluntariamente, quando a evidenciação de informações é feita por espontaneidade da empresa, mesmo que seja com base em diretrizes e orientações.

Segundo Piacentini (2004, p. 51):

[...] evidenciações voluntárias são meios utilizados pelos investidores para analisar as estratégias e os fatores críticos de sucesso da companhia, tanto no ambiente em que as mesmas estão inseridas, como sob o aspecto competitivo do cenário econômico.

Dessa forma, essas informações evidenciadas voluntariamente servem para a empresa demonstrar aos seus usuários o que está sendo feito para a melhoria e a manutenção do bem-estar da comunidade.

Assim, a evidenciação ambiental expõe como os direitos e obrigações da empresa estão sendo administrados para realçar o atendimento dos direitos da sociedade (CASTELO, et al., 2008; RAHAMANA; LAWRENCE; ROPER, 2004; HASSELDINE; SALAMA; STEVEN, 2005; CORMIER et al., 2004; VILLIERS, STADEN, 2006).

0 convivio entre empresa e meio ambiente é próprio de cada contexto pelo qual a evidenciação ambiental irá variar de empresa para empresa (FREEDMAN, PATTEN, 2004; FREEDMAN, STABLIANO, 2008).

Pela ótica construtivista, a evidenciação ambiental é considerada como um processo educativo (GRAY; MURRAY; POWER, 2006) e, assim, é um processo em que a organização e a sociedade permanecem em constante comunicação e aprendizagem sobre suas causas, efeitos, formas de controle e comprometimento de ambos numa visão sociopolítica. (DEEGAN, 1997; CORMIER et al., 2004; HASSELDINE e SALAMA, 2005; TILT, 2001).

Nesta pesquisa consideram, portanto, que a evidenciação ambiental é constituída pelo conjunto de meios utilizados pela empresa para divulgar suas ações e reações para demonstrar o que e como está procedendo com relação ao meio ambiente e à sociedade; também pode ser vista como um instrumento que visa examinar o perfil das informações ambientais apresentadas pelas empresas para suas partes interessadas (GRAY et al., 2001; STRAY, 2008; BRANCO et al., 2008; CORMIER et al., 2004; De VILLIERS; VAN STADEN, 2006; HASSELDINE; SALAMA; STEVEN, 2005; CAMPBELL, 2004; DEEGAN, 1997; FREEDMAN e STAGLIANO, 2008; HARTE, 1991; ROGER; BURRIT, 1997; SAÍDA, 2009; TILT, 2006; TILT et al., 1999).

Assim, informação eficiente é entendida como aquela que revela a gestão ambiental da organização, como: dados sobre itens patrimoniais e de resultados; dados sobre consumo de recursos naturais; dados sobre emissões; dados sobre impactos; dados sobre responsabilidade socioambiental, e dados sobre questões político-institucionais.

Com base nessas considerações, a atual pesquisa visa identificar a evidenciação voluntária de empresas de papel e celulose.

\section{Enquadramento e procedimentos metodológicos}

A seção sobre a metodologia da pesquisa apresenta todo o desenvolvimento do trabalho. Visa expor e explicar detalhadamente todos os passos seguidos para a elaboração e a construção do estudo. Sendo assim, apresentam-se o enquadramento metodológico, a população e a amostra, os procedimentos para coleta e análise dos dados, e delimitação e limitação da pesquisa.

\subsection{Enquadramento e procedimentos metodológicos}

Uma das formas de expor a metodologia de um estudo é definindo seus objetivos. Esta pesquisa é de natureza descritiva, pois são analisadas determinadas características (práticas ambientais) nas divulgações dos Relatórios de Sustentabilidade (RS) e nos sites das empresas selecionadas. Essas variáveis são analisadas, descritas, comparadas por meio da interpretação dos dados coletados e, assim, se chega a uma conclusão quanto à evidenciação, por parte das empresas de papel e celulose, das práticas ambientalmente responsáveis.

Para Gil (1991), a pesquisa descritiva visa descrever as características de determinada população ou fenômeno, ou o estabelecimento de relações entre variáveis. Envolve o uso de técnicas padronizadas de coleta de dados: questionário e observação sistemática. Assume, em geral, a forma de Levantamento. Nesta pesquisa, faz-se uso da observação dos Relatórios de Sustentabilidade (RS), a partir dos quais são levantados os dados referentes às práticas ambientalmente responsáveis. 
0 problema abordado é explorado de forma qualitativa. A pesquisa qualitativa é basicamente aquela que busca entender um fenômeno específico em profundidade. Em vez de estatísticas, regras e outras generalizações, a qualitativa trabalha com descrições, comparações e interpretações. Portanto, este estudo busca identificar e analisar a amostra em questão, com vistas a verificar quais práticas são mais desenvolvidas a partir da evidenciação e quais empresas mais divulgam.

A coleta dos dados é realizada pela técnica de Análise de Conteúdo, por meio da leitura de sentenças em fontes caracterizadas como secundárias - sites das empresas brasileiras de papel e celulose e Relatórios Anuais de Sustentabilidade. Pode-se definir como fonte secundária todo trabalho baseado em outro, sendo este considerado a fonte original ou primária. Dessa forma, tem como característica o fato de não produzir uma informação original, mas trabalhar sobre ela, procedendo a análise, ampliação, comparação, etc.

No trabalho em questão, os sites das empresas pesquisadas e os respectivos Relatórios de Sustentabilidade são tecnicamente analisados a fim de localizar indicadores que permitam construir conhecimento acerca das práticas ambientais em ambos os canais de comunicação utilizados pelas empresas pesquisadas.

Primeiro, fez-se a análise de conteúdo dos relatórios de sustentabilidade, visando identificar as principais informações evidenciadas pelas empresas de papel e celulose. Essa busca resultou em 32 elementos de verificação da evidenciação ambiental, apontados no Quadro 1.

A presença desses elementos será investigada nos Relatórios de Sustentabilidade (RS) e nos sites das empresas. Após a investigação individualizada da evidenciação das práticas ambientais no RS e no site, será feito um cotejamento das informações coletadas nessas duas fontes. Posteriormente, será realizada uma análise identificando o percentual de evidenciação visando identificar qual a maior preocupação dessas empresas: evidenciar essas importantes informações nos sites, nos Relatórios de Sustentabilidade ou em ambos, tanto para os clientes como para os investidores. Paralelamente, a mesma análise será feita individualmente em cada empresa. Após o estudo dos dados coletados, será possível realizar a análise e as considerações finais da pesquisa.

\subsection{População e amostra}

A pesquisa envolve a análise de uma amostra das vinte maiores empresas brasileiras de papel e
Quadro 1. Elementos de evidenciação ambiental analisados na pesquisa.

\begin{tabular}{|c|c|}
\hline & 1. Certificação FSC \\
\hline & 2. Celulose lsenta de Cloro elementar \\
\hline & 3. Sistema de queima de Gases \\
\hline & 4. Unidade de Cogeração de energia \\
\hline & 5. Dentro de todas as normas ambientais \\
\hline & $\begin{array}{l}\text { 6. Pré-branqueameto com } \mathrm{O}_{2} \text { e recuperação de produtos } \\
\text { químicos }\end{array}$ \\
\hline & 7. Combustíveis dos caminhões possuem menor teor de Enxofre \\
\hline & $\begin{array}{l}\text { 8. Utilização de frotas de caminhão não pertencentes à frota } \\
\text { própria }\end{array}$ \\
\hline & 9. Manejo Florestal \\
\hline & 0. Utilização de vias fluviais para o transporte da madeira \\
\hline & 1. Manutenção da biodiversidade \\
\hline & 2. Monitoramento Ambiental em Microbacias \\
\hline & $\begin{array}{l}\text { 3. Projetos focados na Educação Ambiental junto à comunidade } \\
\text { e colaboradores }\end{array}$ \\
\hline & 4. Reciclagem e otimização de recursos \\
\hline & 5. Redução de Emissões Atmosféricas \\
\hline & 6. Sistemas de tratamento de efluentes \\
\hline & 7. Redução da carga específica de DQO e DBO \\
\hline & 8. Redução do consumo de água \\
\hline & 9. Créditos de Carbono \\
\hline & 0. Fomento Florestal - parceria com produtores \\
\hline & 1. Respeito na ocupação do solo \\
\hline & 2. Colheita especializada de forma a reduzir o impacto ambiental \\
\hline & 3. Defensivos agrícolas menos tóxicos \\
\hline & 4. Controle de odores \\
\hline & 5. Projeto contra atropelamento de animais \\
\hline & 6. Monitoramento para evitar impactos ambientais \\
\hline & 7. Pesquisas para manter o desenvolvimento da fauna e flora \\
\hline & 8. Reflorestamento \\
\hline & 9. Programa de recuperação de nascentes e áreas degradadas \\
\hline & 0. Reserva Florestal \\
\hline & 1. Inclui critérios ambientais nos contratos com fornecedores \\
\hline & 2. Construção e manutenção de estradas ecologicamente corretas \\
\hline
\end{tabular}

celulose em se tratando de Patrimônio Líquido no ano de 2006, segundo a edição anual do "Valor 1000", publicada pelo Jornal Valor Econômico, 2007. Essa amostra é derivada de uma população que engloba as mil maiores empresas do Brasil, publicada por esse jornal. Para analisar o mesmo segmento, são selecionadas todas as empresas do ramo de papel e celulose que, devido às suas atividades, possuem um alto poder de degradação ambiental. São elas: VCP, Aracruz Celulose, Klabin, Veracel, Ripasa, Cenibra, Rigesa, International Paper, Orsa, Norske Pisa, Trombini Embalagens, Adami, Irani, Santher, Penha, Mili, Melhoramentos, Rubi, SPP Agaprint e Jari Celulose. 
A decisão de pesquisar esse ramo industrial deveu-se ao fato de as empresas de papel e celulose utilizarem diretamente o meio ambiente como fonte de matéria-prima e, por isso, necessitarem de mais cuidados para manter um desenvolvimento sustentável e, consequentemente, uma maior valorização no mercado.

Como já referido, este estudo é delimitado por uma amostra das vinte maiores empresas de papel e celulose do Brasil em se tratando de Patrimônio Líquido no ano de 2006, segundo a edição anual de "Valor 1000", publicada pelo Jornal Valor Econômico, em agosto de 2007. Portanto, as conclusões obtidas com este trabalho não devem ser generalizadas para todas as empresas desse ramo, pois há uma delimitação no número e no porte das empresas desse setor, segundo a classificação do Jornal Valor Econômico.

Por ser um tema de interesse para diferentes profissionais - contadores, gestores de empresas, administradores - e também investidores e consumidores em geral, este trabalho não tem a intenção de abarcar todo o assunto. Assim, durante a coleta dos dados, algumas limitações foram surgindo.

A empresa Ripasa, por exemplo, está com seu site em construção, fato que impossibilitou o andamento da pesquisa, uma vez que o site da empresa é um dos documentos analisados neste estudo. Outra limitação está no site da National Paper, que se encontra construído em inglês, impossibilitando, assim, uma pesquisa completa e detalhada devido às dificuldades de tradução. Outra limitação são as empresas que não possuem Relatórios de Sustentabilidade ou que não foi possível o acesso a estes. Para todas essas organizações, foram enviados e-mails ou solicitações pelos próprios sites no link "Fale Conosco", pedindo os RS. Do universo de dez empresas, somente duas responderam aos e-mails (International Paper e Penha), dizendo que não possuíam esse documento. As demais não se manifestaram.

Diante das limitações apresentadas, é possível realizar a análise dos resultados da pesquisa dos sites de 18 empresas: VCP, Aracruz, Klabin, Veracel, Cenibra, Rigesa, International Paper, Orsa, Trombini Embalagens, Adami, Irani, Santher, Penha, Mili, Melhoramentos, Rubi, SPP Agaprint e Jari Celulose. 0 estudo dos relatórios e o cotejo das informações são feitos com oito empresas, pois somente estas possuíam os RS: VCP, Aracruz, Klabin, Veracel, Cenibra, Orsa, Irani e Jari Celulose.

A pesquisa analisa, portanto, Relatórios de Sustentabilidade e sítios eletrônicos referentes ao ano de 2007 das 18 empresas da amostra.

\section{Apresentação e análise dos resultados}

Primeiramente, verificou-se a existência de evidenciação nos Relatórios de Sustentabilidade (RS); em um segundo momento, verificou-se a existência de evidenciação nos sites das empresas. Após a investigação individualizada da evidenciação das práticas ambientais no RS e no site, é apresentado, na sequência, o cotejamento das informações coletadas nessas duas fontes. Finalmente, apresenta-se um breve estudo individual das empresas selecionadas.

\subsection{A evidenciação nos relatórios de sustentabilidade (RS)}

Verificou-se então que, das vinte empresas analisadas, apenas oito possuíam o Relatório de Sustentabilidade, conforme o Quadro 2, portanto, deixam de compor a amostra a empresa Ripasa pois o site encontrava-se em construção no momento da coleta de dados, já a empresa National Paper. o site está em inglês. As empresas International Paper e Penha responderam o e-mail mas não possuem relatório de sustentabilidade, e por fim, as empresas: Rigesa, Trombini Embalagens, Adami, Santher, Mili, Melhoramentos, Rubi e SSP Agaprint não responderam e-mail. Infelizmente, no Brasil, a elaboração desse tipo de demonstração ainda é pouco utilizada. A decisão de não elaborar o RS pode dar-se por diversos motivos. Dentre eles, citam-se o custo/benefício de expor essas informações, a necessidade de manter sigilo sobre certos aspectos comerciais ou estratégicos, a não obrigatoriedade, a não contemplação dos requisitos solicitados na Lei n. 6.404/76, ou até mesmo a falta de conhecimento, habilidade ou estrutura para a elaboração desse documento.

Entretanto, aqueles que o fazem podem trazer muitos benefícios para a organização, pois os Relatórios de Sustentabilidade contemplam informações sobre a posição patrimonial e financeira, o resultado, o fluxo financeiro, as práticas voltadas para o desenvolvimento sustentável e valores adotados. Enfim, reúnem condições de entendimento para uma gama bem maior de usuários, trazendo informações sobre o passado, o presente e o futuro da empresa.

De forma geral, os relatórios são semelhantes no que tange à forma de expressão, dando preferência a informações, relatos e ilustrações que refletem os impactos positivos da empresa sobre o meio ambiente e a sociedade, e ao uso de termos técnicos para esclarecimentos detalhados dos procedimentos e práticas ambientais. Há também outra semelhança: limitam-se a apresentar os objetivos alcançados e 
Quadro 2. Evidenciação das empresas nos Relatórios de Sustentabilidade.

\begin{tabular}{|c|c|c|c|c|c|c|c|c|}
\hline & $\mathrm{VCP}$ & Arac. & Klab. & Ver. & Cen. & Ors. & Iran. & J.C. \\
\hline \multicolumn{9}{|l|}{ Certificação FSC } \\
\hline \multicolumn{9}{|l|}{ Celulose isenta de cloro elementar } \\
\hline \multicolumn{9}{|l|}{ Sistema de queima de gases } \\
\hline \multicolumn{9}{|l|}{ Unidade de cogeração de energia } \\
\hline \multicolumn{9}{|l|}{ Dentro de todas as normas ambientais } \\
\hline \multicolumn{9}{|l|}{ Pré-braqueamento com $\mathrm{O}_{2}$ e recuperação de produtos químicos } \\
\hline \multicolumn{9}{|l|}{ Combustíveis dos caminhões possuem menor teor de enxofre } \\
\hline \multicolumn{9}{|l|}{ Ultilização de frotas de caminhão não pertencentes à frota própria } \\
\hline \multicolumn{9}{|l|}{ Manejo florestal } \\
\hline \multicolumn{9}{|l|}{ Ultilização de vias fluviais para o transporte de madeira } \\
\hline \multicolumn{9}{|l|}{ Manutenção da biodiversidade } \\
\hline \multicolumn{9}{|l|}{ Monitoramento ambiental em microbacias } \\
\hline \multicolumn{9}{|l|}{ Projetos focados na educação ambiental junto à comunidade } \\
\hline \multicolumn{9}{|l|}{ Reciclagem e otimização de recursos } \\
\hline \multicolumn{9}{|l|}{ Redução de emissões atmosféricas } \\
\hline \multicolumn{9}{|l|}{ Sistema de tratamento de efluentes } \\
\hline \multicolumn{9}{|l|}{ Redução de carga especifica de DQO e DBO } \\
\hline \multicolumn{9}{|l|}{ Redução de consumo de água } \\
\hline \multicolumn{9}{|l|}{ Créditos de carbono } \\
\hline \multicolumn{9}{|l|}{ Fomento florestal - parceria com produtores } \\
\hline \multicolumn{9}{|l|}{ Respeito na ocupação do solo } \\
\hline \multicolumn{9}{|l|}{ Colheita especializada de forma a reduzir o impacto ambiental } \\
\hline \multicolumn{9}{|l|}{ Defensivos agricolas menos tóxicos } \\
\hline \multicolumn{9}{|l|}{ Controle de odores } \\
\hline \multicolumn{9}{|l|}{ Projeto contra atropelamento de animais } \\
\hline \multicolumn{9}{|l|}{ Monitoramentos para evitar impactos ambientais } \\
\hline \multicolumn{9}{|l|}{ Pesquisas para manter o desenvolvimento de fauna e flora } \\
\hline \multicolumn{9}{|l|}{ Reflorestamento } \\
\hline Programa de recuperação de nascentes e áreas degradadas & & & & & & & & \\
\hline Reserva florestal & & & & & & & & \\
\hline Inclui críterios ambientais nos contratos com fornecedores & & & & & & & & \\
\hline Construção e manutenção de estradas ecologicamente corretas & & & & & & & & \\
\hline
\end{tabular}

VCP (Votorantim), Arac. (Aracruz), Klab. (Klabin), Ver. (Veracel), Cen. (Cenibra), Ors. (Orsa), Iran. (Irani) e J.C. (Jari Celulose). Fonte: Dados da pesquisa.

traçados de forma descritiva, sem apresentar sua interação com as estratégias da empresa no curto, médio e longo prazo.

As práticas ambientais desenvolvidas pelas empresas selecionadas foram examinadas nos Relatórios de Sustentabilidade por meio da análise de conteúdo, tendo como unidade de medida as sentenças. Foram observados os elementos de evidenciação selecionados e demonstrados nos procedimentos metodológicos desta pesquisa, conforme o Quadro 1.

0 Quadro 2 exibe as práticas encontradas na análise do conteúdo dos RS das vinte empresas da amostra.

No Quadro 2, foram destacadas as práticas ambientais que constam nos Relatórios de Sustentabilidade de cada empresa analisada. A Figura 1 tem como finalidade facilitar a interpretação do Quadro 2, pois fica mais fácil identificar quais são as práticas mais utilizadas pelas organizações em análise.

Verifica-se que as práticas mais evidenciadas são "Reserva florestal", "Pesquisas para manter o desenvolvimento da fauna e da flora", "Monitoramento para evitar impactos ambientais", "Fomento florestal", "Manejo florestal" e "Estar dentro das normas ambientais". As práticas menos evidenciadas são "Projeto contra atropelamento de animais", "Utilização de frota de caminhão não pertencente à frota própria", "Combustíveis dos caminhões produzem menor teor de enxofre" e "Pré-branqueamento com 02 e recuperação de produtos químicos". Observa-se que as práticas "Inclui critérios ambientais nos contratos com fornecedores" e "Programa de recuperação de nascentes e áreas degradadas" não foram 

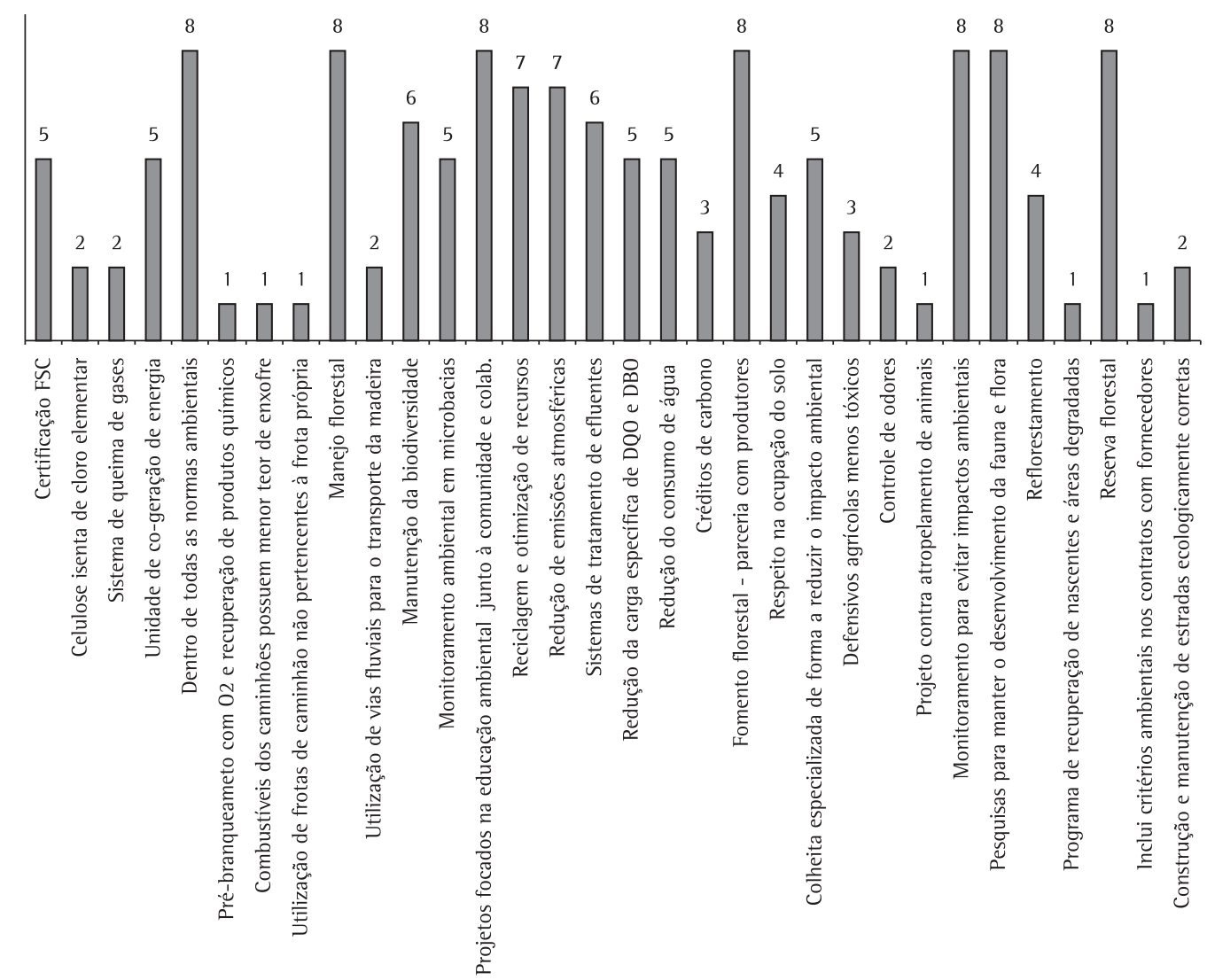

Figura 1. Evidenciação das práticas socioambientais nos Relatórios de Sustentabilidade das Empresas. Fonte: Dados da Pesquisa.

evidenciadas por nenhuma empresa no respectivo Relatório de Sustentabilidade.

Diante da limitação encontrada e no intuito de localizar os relatórios não disponibilizados nos sites das empresas, foi enviado e-mail para todos os contatos indicados nas páginas da web de cada organização. Foi obtido retorno de apenas três empresas, que informaram não possuir esse tipo de documento. Os demais, que tiveram um tempo hábil de mais de dois meses para retornarem a mensagem, não responderam; por isso, os RS dessas organizações foram considerados como inexistentes.

Verificou-se que, dos 32 elementos de evidenciação analisados nesta pesquisa, 18,15\% foram citados em todas as empresas em questão. Tais elementos de evidenciação são: "Manejo Florestal", "Fomento Florestal", "Estar dentro de todas as Normas Ambientais", "Reserva Florestal”, "Projetos focados na Educação Ambiental" e "Pesquisas para manter o Desenvolvimento da Fauna e da Flora". Para ilustrar essa constatação, reproduzem-se, a seguir, alguns exemplos de evidenciação dessas práticas. Para facilitar o acompanhamento do processo de identificação das práticas nos excertos abaixo, as indicações - explícitas e implícitas - são salientadas em negrito:

Em nosso projeto de crescimento também buscamos a colaboração de produtores rurais, que participam de um programa de fomento florestal. Desde o início da iniciativa, em 1984, distribuímos 109 milhões de mudas de pínus e eucalipto, para o plantio de aproximadamente 60 mil hectares de florestas. Essa é uma forma de auxiliar na ampliação de renda e fixação do homem no campo, além de recuperar áreas com cobertura florestal. (KLABIN, 2006, p. 16).

Também cumpre integralmente a legislação ambiental em vigor e estabelece diálogo transparente e pró-ativo com os órgãos ambientais brasileiros e as ONGs vinculadas ao tema. Por meio de rigoroso acompanhamento, a companhia garante a segurança necessária para que sua atuação previna impactos ambientais, o que a leva a ter um dos melhores desempenhos ambientais do mundo em produção de celulose (VERACEL, 2006, p. 45). 
Após verificar todas as práticas citadas nos relatórios, observou-se também que algumas são específicas da organização, como, por exemplo, a "Utilização de vias fluviais para o transporte de madeira”. Tal prática depende da localização geográfica de cada empresa. Outras, entretanto, são realmente inovadoras, como o "Programa que previne o atropelamento de animais", citado pela empresa Cenibra, e o "Combustível menos poluente utilizado na frota de caminhões”, da Votorantim.

De maneira geral, os Relatórios são extensos e possuem, em média, 65 páginas. A maioria, com tradução para o inglês. Nessas páginas, foram encontradas informações, como visão estratégica, apresentação, perspectivas, desempenho, investimentos, estruturas, premiações, entre outras. Devido ao fato de as empresas analisadas explorarem intensamente o meio ambiente para extração e produção de matéria-prima, é considerável o número de páginas destinadas às práticas ambientais adotadas. Muitas das práticas são obrigatórias em virtude das leis; outras, contudo, são expostas com orgulho, como algo a mais, a fim de valorizar a imagem da organização.

Curiosamente - e seguindo o mesmo raciocínio acima -, foi verificado que apenas três dos relatórios possuiam um item em que se constatavam claramente multas, ações judiciais ou ocorrências ambientais sofridas pela empresa. Percebeu-se ainda que, logo após essas descrições, eram informadas as atitudes tomadas para solucionar o problema, assim como o valor desembolsado. As três empresas são a Votorantim, a Veracel e a Aracruz.

Diante das análises realizadas, pode-se afirmar que os RS, apesar de não serem muito comuns nas empresas do ramo de papel e celulose (visto que apenas $40 \%$ o possuíam), são de fácil acesso dentro dos sites de cada organização, abrangem informações detalhadas e buscam realmente apresentar informações passadas, traçando uma perspectiva futura, sempre de maneira positiva.

\subsection{A evidenciação nos sites das empresas analisadas}

0 mesmo procedimento utilizado na análise da evidenciação do RS é desenvolvido, quando da análise dos sites das empresas. Essa etapa da pesquisa revelou resultado bem diferente daqueles encontrados quando da análise nos Relatórios de Sustentabilidade. Verifica-se que apenas quatro empresas não apresentam informações sobre as práticas ambientais no site. Adicionalmente, todas as empresas evidenciam, no site, as práticas socioambientais formuladas nesta pesquisa.

Conforme já mencionado, poucas das empresas pesquisadas possuíam os Relatórios de Sustentabilidade. Esse comportamento é contrário ao constatado nos sites das empresas, nos quais a grande maioria cita as práticas ambientais realizadas.

A prática ambiental mais representativa na análise dos sites da amostra foi: "Projetos focados na educação ambiental junto à comunidade e colaboradores" e a empresa que mais se destacou, citando 24 práticas, foi a Aracruz.

0 item que mais apareceu nas empresas analisadas foi a preocupação com "Projetos focados na educação ambiental junto à comunidade e colaboradores", seguido do "Monitoramento para evitar impactos ambientais", que só não foi citado pela empresa Melhoramentos. Em contrapartida, os itens "Utilização dos combustíveis dos caminhões com menos teor de enxofre" e "Programa contra atropelamento de animais" foram práticas citadas somente uma vez.

Observa-se que a evidenciação das práticas diminui proporcionalmente à colocação das empresas no ranking. Uma das razões para essa ocorrência é o fato de algumas não trabalharem diretamente com a produção de matéria-prima, mas somente com a transformação, não realizando o processo produtivo completo. De fato, o número de leis ambientais para essas organizações que compram em vez de produzirem matéria-prima acaba sendo menor, não havendo, portanto, a necessidade de divulgar e realizar práticas que fogem de suas responsabilidades. Certamente, pela lei, essas empresas têm suas responsbilidades ambientais reduzidas, porém isso não as impede de ir além, de não só realizar como também divulgar tudo aquilo que praticam para manter a preservação do meio ambiente. Dessa forma, além de melhorarem sua imagem, incentivam a comunidade e todas as outras empresas, independentemente de serem livres ou não de leis ambientais específicas.

Mantendo ainda o mesmo raciocínio, as organizações que adquirem matéria-prima poderiam também avaliar seus fornecedores, medindo suas responsabilidades ambientais e divulgando esse critério, o que indiretamente afetaria a concorrência, além de influenciar a população para seguir o mesmo critério quando da aquisição de produtos e/ ou serviços.

Infelizmente, esta pesquisa teve como limitação o proceder de algumas empresas, que não seguiram esse pensamento e divulgaram práticas de maneira 
genérica e pouco detalhadas; ou seja, insuficientes para alimentar o Quadro montado. São elas: Mili, Penha, Rubi e SPP Agraprint, pertencentes, respectivamente, às seguintes colocações no ranking: $15^{\circ}, 16^{\circ}, 18^{\circ}$ e $19^{\circ}$. Para exemplificar, segue o único trecho da empresa Mili que fala sobre meio ambiente:"A Mili preocupa-se com seu papel junto à sociedade e desenvolve uma série de iniciativas dentro do conceito de Responsabilidade Social. As ações envolvem, principalmente, a preservação do meio ambiente".

Apesar dessa limitação e de outras duas encontradas - na empresa Ripasa, cujo site estava em construção, e na International Paper, cujo site estava escrito em inglês -, de maneira geral, a pesquisa revela que os sites das empresas da amostra apresentam configuração amigável, que possibilita, de forma simplificada, o acesso às informações pesquisadas.

\subsection{Cotejamento das informações coletadas nos sites de evidenciação e nos relatórios de sustentabilidade}

Considerando que a evidenciação das práticas ambientais e sociais se configura como atitude fundamental no que tange à transparência de ações e ao comprometimento para com seus acionistas e investidores, e considerando, também, que o RS e o site configuram-se como canais diretos de comunicação com acionistas e investidores, nada mais natural do que a convergência de informações divulgadas nessas duas fontes. Sendo assim, esta subseção objetiva proceder ao cotejamento das informações coletadas nos sites de evidenciação e nos relatórios de sustentabilidade.

Após o cotejo das informações, verifica-se que as práticas "Reserva natural", "Monitoramento para evitar impactos ambientais", "Redução de emissões atmosféricas" e "Projetos focados na educação ambiental junto à comunidade e colaboradores" tiveram destaque, pois foram citadas tanto nos sites como nos RS das oito empresas estudadas. Dessa forma, essas informações têm representatividade de $74 \%$ em ambos os documentos analisados, seguidas de 14\% de informações mencionadas somente nos Relatórios de Sustentabilidade e de 12\%, apenas nos sites estudados.

0 resultado revela ainda que a maioria das empresas pesquisadas preocupa-se em divulgar suas ações voltadas para o Desenvolvimento Sustentável em ambos os meios de comunicação estudados. Informar seus clientes e o público em geral por meio de seus sites é tão importante quanto divulgar a mesma informação para aqueles que, com outros objetivos, necessitam de informações mais detalhadas, como os acionistas, investidores e, até mesmo, especuladores.

A pesquisa apresentou um percentual semelhante ao das informações encontradas somente nos sites como aquelas divulgadas nos Relatórios. A diferença de apenas $2 \%$ não era esperada. Tal expectativa deve-se ao fato de os RS serem teoricamente muito mais detalhados que as descrições encontradas nos sites. Tal detalhamento é inevitável, visto que o objetivo principal deste documento é informar minuciosamente todas as medidas tomadas para o desenvolvimento sustentável da organização, assim como seus objetivos, valores e metas futuras.

Esse descompasso com os resultados da pesquisa pode ser atribuído à empresa Aracruz, que indicou oito das 21 práticas divulgadas somente nos sites, o que representa 38,09\%. Se excluída a Aracruz do estudo, o resultado seria diferente: $75 \%$ em ambos, $17 \%$ em relatórios e $8 \%$ em sites. Esses novos números estariam de acordo com o raciocínio lógico explicado acima. No tópico seguinte, é realizado um estudo individual do resultado de cada empresa pesquisada.

Analisando-se ainda o resultado geral, pode-se dizer que, conforme a empresa diminui sua colocação no ranking, menores são os investimentos focados na preservação ambiental, o que afeta proporcionalmente a apresentação dos Relatórios Anuais de Sustentabilidade, assim como as práticas ambientais como um todo. A organização, por ser menor, deve ter uma produção reduzida, assim como a exploração que necessita para obter suas matériasprimas no meio ambiente. Consequentemente, a degradação que causa também é inferior. Logo, as medidas que devem ser tomadas para garantir a sustentabilidade acabam seguindo a mesma lógica, o que explica, de certa forma, a diminuição das práticas se comparadas com as das empresas que ocupam as primeiras colocações no ranking.

Diante da atual situação mundial, no que se refere ao meio ambiente, existe uma grande conscientização por parte da população; ou seja: diante das diversas campanhas, estudos, inúmeros alertas e, até mesmo, sob leis criadas a favor do meio ambiente, o perfil - não somente de empresários, mas também de clientes, investidores e consumidores - vem mudando ao longo dos anos. Nota-se que quanto mais as organizações investem nessas práticas ambientais, mais valor se dá a elas, pois garantem a possibilidade de desenvolvimento para as gerações futuras. E é exatamente seguindo esse raciocínio que se pode justificar o resultado desta pesquisa: a grande maioria das empresas 
estudadas dá preferência por evidenciar as práticas ambientais por meio de dois importantes canais de evidenciação, que são acessíveis por todo o público com quem se relacionam, como fornecedores, clientes, comunidade, investidores, acionistas, colaboradores e especuladores.

Com base no resultado geral observado, é feito um breve estudo individual das empresas aqui analisadas.

\subsection{Análise por empresa}

Este estudo individual irá apresentar a frequência de evidenciação de cada empresa com relação às fontes investigadas: o RS e o site. Com exceção da empresa Klabin, as outras sete organizações estudadas seguiram a mesma linha dos números obtidos na análise geral.

Visando à maior competitividade no mercado, as organizações utilizam-se de importantes meios de comunicação para evidenciar junto ao público com o qual elas se relacionam, as diferentes práticas voltadas ao desenvolvimento sustentável. Dessa forma, seus Relatórios de Sustentabilidade e sites fornecem informações aos clientes, acionistas, investidores, especuladores, fornecedores, colaboradores e comunidade não só do cumprimento da legislação vigente no que tange às questões do meio ambiente, mas também daquilo que é praticado além da exigência de lei. Essa atitude responsável assegura uma boa imagem às organizações, preserva o meio ambiente e possibilita um diferencial competitivo perante a concorrência.

A empresa Votorantim, recebendo o destaque de primeira colocação, segundo o ranking da edição anual do "Valor 1000", publicada pelo Jornal Valor Econômico, em agosto de 2007, apresentou números favoráveis na análise realizada individualmente. Das práticas que realiza, 77\% são evidenciadas nos sites e nos RS, 19\% somente nos relatórios e apenas $4 \%$ nos sites. Esses números seguem o raciocínio lógico já apresentado, ou seja, divulgar de maneira igualitária as informações em ambos os meios de comunicação. Contudo, cabe ao RS desenvolver uma descrição mais detalhada, o que aumenta seu percentual no resultado final.

Já a empresa Aracruz Celulose apresentou um resultado bem atípico, em que $67 \%$ das práticas foram divulgadas em ambos os meios analisados e 33\% foram evidenciadas somente nos sites. A esse resultado, podem-se atribuir diversos motivos, como a valorização das informações apresentadas nos sites, a não preocupação em mostrar as iniciativas voltadas para o desenvolvimento ambiental no Relatório de Sustentabilidade, falhas na elaboração do Relatório, entre outros. A Aracruz considera a diferenciação conferida pelos seus Ativos Intangíveis um crescente fator de competitividade.

E, finalmente, uma razão justificável - não somente na Aracruz, mas em todas as empresas analisadas - é a atualização desses documentos analisados. Os Relatórios Anuais de Sustentabilidade são elaborados e não mais modificados, ao contrário dos sites, que podem ser atualizados diariamente, e, portanto, possuírem informações não citadas em determinado momento nos respectivos Relatórios Anuais.

Nesta pesquisa, foi possivel perceber que a Klabin foi a única empresa a obter um resultado em que $100 \%$ das práticas ambientais foram divulgadas em ambos os documentos estudados. Esse resultado é extremamente positivo, pois demonstra possuir a mesma preocupação com os diversos públicos com os quais se relaciona, além de manter uma importante coerência nas informações apresentadas.

Essa forma de divulgação serve como exemplo a ser seguido por todas as organizações que utilizam os Relatórios de Sustentabilidade, pois, dessa forma, é possível transmitir a mesma informação, porém de maneiras diferentes a todos os interessados em conhecer as diversas práticas desenvolvidas pela empresa. Esse fato pode ser apenas uma das justificativas que faz com que a Klabin seja uma das líderes no mercado brasileiro.

A Klabin é a maior produtora, exportadora e recicladora de papéis do Brasil. Líder nos mercados de papéis e cartões para embalagens, embalagens de papelão ondulado e sacos industriais, também produz e comercializa madeira em toras.

A Veracel apresentou um resultado muito parecido com a Votorantim, em que há a predominância nas divulgações em ambos (81\%), seguido das práticas evidenciadas apenas nos RS (14\%) e, posteriormente, as divulgadas somente nos sites (5\%).

Esse resultado confirma o pensamento que segue a lógica encontrada no estudo realizado, ou seja, a grande maioria divulgada em ambos os meios, seguido daquelas divulgadas apenas nos RS e depois nos sites.

Segundo dados divulgados pela Veracel, esta empresa quer ser uma referência mundial em sustentabilidade e destacar-se como uma empresa ambientalmente correta, socialmente justa e economicamente viável.

A Cenibra possui um excelente resultado de evidenciação: aproximadamente $85 \%$ dos itens 
divulgados no Relatório de Sustentabilidade também estão divulgados no site da empresa. De maneira geral, seguiu-se o mesmo raciocínio da Votorantim e da Veracel. A Cenibra foi a empresa que apresentou um site muito bem elaborado: de maneira clara e prática, foi fácil encontrar as práticas voltadas para o desenvolvimento sustentável.

A empresa Orsa, ocupante do nono lugar no ranking das maiores empresas, já possui um resultado um pouco diferenciado. Além de aplicar poucas medidas voltadas para a sustentabilidade ambiental - apenas 14 contra 27 da Votorantim (primeira colocada) -, a organização apresentou um pequeno percentual em se tratando das práticas evidenciadas tanto nos sites quanto nos relatórios.

A empresa Irani, por sua vez, apresenta um total de 19 práticas evidenciadas e um site pouco detalhado no que se refere às atitudes que visam à sustentabilidade ambiental. Porém, segue a mesma linha do resultado geral da pesquisa realizada nas oito organizações em questão. Esse resultado, apesar de ser muito parecido com a média da pesquisa em termos percentuais, deixa a desejar devido à quantidade de práticas evidenciadas.

A empresa Jari Celulose segue exatamente a mesma explicação da Orsa Celulose, Papel e Embalagens S.A. Ambas pertencem ao Grupo Orsa e podem ter suas informações distorcidas pelo mesmo motivo: utilizar um único Relatório Anual de Sustentabilidade para todas as empresas do grupo. A Jari Celulose S.A., no desenvolvimento de seus processos florestais, tem como política atender à demanda por seus produtos, utilizando tecnologias que assegurem qualidade, produtividade e competitividade em harmonia com o meio ambiente.

\section{Considerações finais}

0 presente trabalho objetivou investigar a evidenciação voluntária das práticas voltadas para o desenvolvimento sustentável nas vinte maiores empresas brasileiras de Papel e Celulose, em se tratando de Patrimônio Líquido no ano de 2006, segundo a edição anual do "Valor 1000", publicada pelo Jornal Valor Econômico, em agosto de 2007.

Para o alcance do objetivo deste estudo, a investigação foi conduzida por meio das análises de conteúdo realizadas no site e no Relatório de Sustentabilidade de cada empresa. Apesar das limitações encontradas, os resultados apontaram que a maioria das empresas divulga as práticas ambientais realizadas em ambos os meios de comunicação estudados: sites e Relatórios Anuais de Sustentabilidade.
0 Relatório de Sustentabilidade é o melhor meio para informar acionistas, investidores, especuladores e até mesmo aqueles que desejam obter informações mais detalhadas no que tange ao passado da organização assim como os planos e metas futuras. Neste, é evidenciado também tudo aquilo que numericamente não foi possivel, os chamados Ativos Intangíveis. Infelizmente, a Contabilidade enfrenta grandes dificuldades ao lidar com intangíveis, tanto para mensurá-los como para divulgá-los de maneira textual por meio dos Relatórios. Talvez, por esse motivo, este estudo tenha enfrentado limitações, como, por exemplo, a inexistência de RS em 12 das vinte organizações analisadas.

A pesquisa demonstra a importância dada às práticas ambientais nos tempos atuais. Diferentemente do que se pensava no passado, o crescimento econômico vem sendo incentivado até por ambientalistas, que acreditam cada vez mais na sua sustentabilidade. Criado oficialmente desde 1987, o desenvolvimento sustentável vem sendo um dos assuntos mais discutidos dentro das organizações que agora reconhecem a inviabilidade de crescimento sem a preocupação com as gerações futuras.

Diante desse fato, as empresas passaram a investir fortemente nas práticas ambientais. Muitas vezes obrigadas por leis, outras por iniciativa própria, visando também à sua valorização no mercado e, até mesmo, à vantagem perante a concorrência, essas organizações comprometem-se em assegurar uma melhor qualidade de vida para seus clientes.

A pesquisa revela que, das práticas ambientais, $74 \%$ foram divulgadas em ambos os documentos analisados, 14\% somente nos Relatórios de Sustentabilidade e $12 \%$ apenas no site. Os RS, por serem mais detalhados e utilizarem termos mais técnicos, acabam evidenciando mais que os sites, pois os últimos fazem uso de uma linguagem mais simples e generalizada, para o bom entendimento dos diversos leitores.

Em destaque na pesquisa realizada, temos as práticas "Reserva natural", "Monitoramento para evitar impactos ambientais", "Redução de emissões atmosféricas" e "Projetos focados na educação ambiental junto à comunidade e aos colaboradores", que foram citadas tanto nos sites como nos RS das oito empresas estudadas.

A Votorantim foi a empresa que mais divulgou práticas em ambos os meios, um total de 27 , e a Klabin foi a única que divulgou exatamente as mesmas práticas nos sites e nos Relatórios de Sustentabilidade, totalizando vinte. 
Esta pesquisa buscou traçar o perfil da evidenciação das práticas ambientais das empresas do setor de papel e celulose. Embora os autores reconheçam que os objetivos tenham sido atingidos, estando em conformidade com as definições de Evidenciação Ambiental reconhecida cientificamente, consideram que os critérios de seleção são específicos para este tipo de empresa e decorrem das informações obtidas nos Relatórios das próprias empresas. Consideram também que pesquisas futuras possam aliar essas informações às diretrizes de evidenciação ambiental de organizações, como Índice de Sustentabilidade Empresarial (ISE), Global Reporting Initiative (GRI), Dow Jones Index, entre outros, além das normas de evidenciação, como ISAR, IBRACON e NBCT15. A esmagadora maioria dos pesquisadores em evidenciação ambiental vale-se de normas, leis e diretrizes para medir o grau de evidenciação ambiental das organizações, apresentando um consenso científico sobre os elementos de Evidenciação Ambiental.

Neste estudo, também foi possível constatar a dificuldade que a contagem de sentenças de critérios pré-estabelecidos pode gerar, ou seja, colocam-se no mesmo patamar informações ambientais positivas e negativas.

Com base nesta análise, os autores percebem como uma oportunidade de contribuição ao assunto a exploração de formas de mensurar os fatores determinantes da explicitação da evidenciação ambiental em forma não ambígua, homogênea, que transmita o entendimento qualitativo da informação ambiental prestada pelas organizações.

Assim, este trabalho leva a considerar que o tema é relevante e emergente, e, nos documentos analisados, é possivel perceber a preocupação das empresas em praticar e divulgar para o público em geral as suas práticas ambientais. Entretanto, o Relatório de Sustentabilidade, apesar de ser um documento contábil oficial, não é auditado; ou seja: as informações ali divulgadas não sofrem qualquer investigação em se tratando da sua veracidade. Por esse motivo, surge o questionamento: até que ponto se pode confiar nessas divulgações? Certamente, não seria vantagem para essas empresas divulgarem informações distorcidas, uma vez que um dos princípios da Responsabilidade Social Corporativa é a transparência que gera credibilidade. Mas como se pode saber se todas as organizações seguem esse princípio?

Diante desse panorama, aponta-se a necessidade de obrigatoriedade de auditoria nos Relatórios Anuais de Sustentabilidade divulgados, seguindo os mesmos procedimentos já realizados nas auditorias das demonstrações contábeis. Sugere-se, portanto, analisar períodos anteriores, a fim de verificar a evolução ao longo dos anos e verificar a relação de evidenciação ambiental e desempenho econômico.

\section{Referências}

ALBERTON, L.; CARVALHO, F.; CRISPIM, G. Evidenciação da responsabilidade social/ambiental da perspectiva de um novo contexto empresarial. Florianópolis: Universidade Federal de Santa Catarina, 2004. Disponível em: <http:// www.congressoeac.locaweb.com.br/artigos42004/151. pdf>. Acesso em: set. 2009.

ARACRUZ. Relatório de sustentabilidade Aracruz 2006. Aracruz, 2006. Disponível em: <www.aracruz.com.br>. Acesso em: out de 2007.

BARATA, M. M. L. Auditoria ambiental no Brasil: uma nova ferramenta de gestão empresarial. Dissetação (Mestrado) - COPPE/UFRJ, Rio de Janeiro, 1995.

BARBIERE, J. C. Gestão ambiental empresarial: conceitos, modelos e instrumentos. 2. ed. São Paulo: Saraiva, 2007.

BRAGA, C. (Org.). Contabilidade ambiental: ferramenta para a gestão da sustentabilidade. São Paulo: Atlas, 2007.

CAMPBELL, D. A longitudinal and cross-sectional analysis of environmental disclosure in UK companies - a research note. The British Accounting Review, v. 36, n. 1, p. 107-117, 2004.

CASTELO BRANCO, B.; EUGÉNIO, T.; RIBEIRO, J. Environmental disclosure in response to public perception of environmental threats: The case of co-incineration in Portugal. Journal of Communication Management, v. 12, n. 2, p. 136-151, 2008.

CENIBRA. Relatório de sustentabilidade Cenibra 2006. [S.I.]: Cenibra, 2006. Disponível em: <www.cenibra.com.br>. Acesso em: out de 2007.

CORMIER, D. et al. Corporate environmental disclosure: contrasting management's perceptions with reality. Journal of Business Ethics, v. 49, n. 2, p. 143-165, 2004.

de VILLIER, C.; van STADEN, C. J. Can less environmental disclosure have a legitimizing effect? Evidence from Africa. Accounting, Organizations and Society, v. 31, n. 8, p. 763-781, 2006.

DEEGAN, C. The materiality of environmental information to users of annual reports. Accounting, Auditing \& Accountability, v. 7, n. 4, p. 47-72, 1997.

FERREIRA, A. C. S. Contabilidade ambiental: uma informação para o desenvolvimento sustentável. São Paulo: Atlas, 2003.

FREEDMAN, M.; PATTEN, D. M. Evidence on the pernicious effect of financial report environmental disclosure. Accounting Forum, v. 28, n. 1, p. 27-41, 2004.

FREEDMAN, M.; STAGLIANO, A. J. Environmental disclosures: electric utilities and Phase 2 of the Clean Air Act. Critical Perspectives on Accounting, v. 19, n. 4, p. 466-486, 2008.

GIL, A. C. Métodos e técnicas de pesquisa social. 5. ed. São Paulo: Atlas, 1999.

GRAY, R. et al. Social and environmental disclosure and corporate characteristics: a research note and extension. Journal of Business Finance \& Accounting, v. 28, n. 1, p. 327-356, 2001.

GRAY, R.; MURRAY, A. D. S.; POWER, D. Do financial markets care about social and environmental disclosure? Further evidence and exploration from the UK. Accounting, Auditing \& Accountability, v. 19, n. 2, p. 228-255, 2006. 
HARTE, G. D. O. Environmental disclosure in the annual reports of british companies: a research note. Accounting, Auditing \& Accountability, v. 4, n. 3, p. 51-61, 1991.

HASSELDINE, J.; SALAMA, A.; STEVEN, T. Quantity versus quality: the impact of environmental disclosures on the reputations of UK Plcs. The British Accounting Review, v. 37, n. 2, p. 231-248, 2005.

IRANI. Relatório de sustentabilidade Irani 2006. [S.I.]: Irani, 2006. Disponível em: <www.irani.com.br>. Acesso em: out. 2007.

JARI CELULOSE. Relatório de sustentabilidade Jari Celulose 2006. [S.l.]: Jari Celulose, 2007. Disponível em: <www. jari.com.br>. Acesso em: out. 2007.

JORNAL VALOR ECONÔMICO. Edição especial "Valor 1000". São Paulo, 2007.

KLABIN. Relatório de sustentabilidade Klabin 2006. [S.1.]: Klabin, 2007. Disponível em: <www.klabin.com.br>. Acesso em: out. 2007.

KOSZTRZEPA, R. 0. Evidenciação dos eventos relacionados com o meio ambiente: um estudo em Indústrias Químicas. 2004. Dissertação (Mestrado em Ciências Contábeis) Universidade do Vale do Rio Sinos, São Leopoldo, 2004.

LINS, L. S.; SILVA, R. N. S. Responsabilidade Sócio-Ambiental ou Greenwash: uma avaliação com base nos relatórios de sustentabilidade ambiental. In: ENCONTRO NACIONAL SOBRE GESTÃO EMPRESARIAL E MEIO AMBIENTE ENGEMA, 9., 2007, Curitiba. Anais...

MARTINS, E. Capital intelectual: verdades e mitos. In: CONGRESSO BRASILEIRO DE CONTABILIDADE, 16, 2000, Goiânia, G0. Anais...

NOSSA, V. Disclosure ambiental: uma análise do conteúdo dos relatórios ambientais de empresas do setor de papel e celulose em nível internacional. 2002. 246. f. Tese (Doutorado em Ciências Contábeis) - Universidade de São Paulo, São Paulo, 2002.

PIACENTINI, N. Evidenciação contábil voluntária: uma análise da prática adotada por companhias abertas brasileiras. 2004. 132. f. Dissertação (Mestrado em
Ciências Contábeis) - Universidade do Vale do Rio dos Sinos - UNISINOS, São Leopoldo, 2004.

RAHAMANA, A. S.; LAWRENCE, S.; ROPER, J. Social and environmental reporting at the VRA: institutionalised legitimacy or legitimation crisis? Critical Perspectives on Accounting, v. 15, n. 1, p. 35-56, 2004.

ROGER, L.; BURRITT, S. W. Australian Commonwealth Entities: an analysis of their environmental disclosures, Acabus, v. 33, n. 1 p. 69-87, 1997.

SAIDA, D. Contribution on the analysis of the environmental disclosure: a comparative study of American and European multinationals. Social Responsability Journal, v. 5. n. 1, p. 83-93, 2009.

SALOTTl, B. M.; YAMAMOTO, M. M. Ensaio sobre a teoria da divulgação. Brazilian Business Review, v. 2, n. 1, p. 53-70, 2005.

STRAY, S. Environmental Reporting: the U.K. Water and Energy Industries: a research note. Journal of Business Ethics, v. 80, n. 4, p. 697-710, 2008.

TILT, C. A. et al. Environmental disclosure by Australian mining companies: environmental conscience or commercial reality? Accounting Forum, v. 23, n. 2, p. 137-154, 1999.

TILT, C. A. Linking environmental activity and environmental disclosure in an organisational change framework. Journal of Accounting \& Organizational Change, v. 2, n. 1, p. 4-24, 2006.

TILT, C. A. The content and disclosure of Australian corporate environmental policies. Accounting, Auditing \& Accountability, v. 14, n. 2, p. 190-212, 2001.

TINOCO, J. E.; KRAEMER, E. P. Contabilidade e gestão ambiental. São Paulo: Editora Atlas, 2004.

VERACEL. Relatório de Sustentabilidade Veracel 2006. [S.I.]: Veracel, 2007. Disponível em: <www.veracel.com.br>. Acesso em: out. 2007.

VOTORANTIM. Relatório de Sustentabilidade Votorantim 2006. [S.1.]: Votorantin, 2007. Disponível em: <www.vcp. com.br>. Acesso em: out. 2007.

\title{
Voluntary disclosure of environmental practices: a study of the largest Brazilian paper and cellulose enterprises
}

\begin{abstract}
This research, aims to investigate the voluntary disclosure of the twenty largest Brazilian paper and cellulose manufacturers. It confirms that the majority of the institutions analyzed are anxious to maintain sustainable development and, above all, to divulge their concern both to customers and to their investors.
\end{abstract}

Keywords

Voluntary environmental disclosure. Enviromental pratices. Pulp and paper. 